\title{
O método de reconhecimento de receita adotado pelas entidades de incorporação imobiliária brasileiras compromete a comparabilidade das demonstrações financeiras?
}

Does the method of revenue recognition adopted by real estate Brazilian developers compromise the comparability of financial statements?

¿El método de reconocimiento de ingresos adoptado por las entidades de incorporación inmobiliaria brasileñas compromete el sistema de comparación de las demostraciones financieras?

\section{Fernanda Belmudes dos Santos}

Bacharel em Ciências Contábeis pela Universidade de São Paulo

Endereço: Rua Ministro João Mendes, 62, apto 24

CEP: 11.040-260 - Santos/SP - Brasil

E-mail: fernanda.belmudes.santos@gmail.com

Telefones: (11) 98169-5910 e (13) 3271-1921

\section{Bruno Meirelles Salotti}

Doutor em Ciências Contábeis pela Universidade de São Paulo

Professor do Departamento de Contabilidade e Atuária da FEA/USP

Endereço: Avenida Prof. Luciano Gualberto, 908, prédio FEA-3 - Cidade Universitária

CEP: 05.508-900 - São Paulo/SP - Brasil

E-mail: brunofea@usp.br

Telefone: (11) 3091-5820

Artigo recebido em 14/12/2012. Revisado por pares em 14/07/2013. Reformulado em 05/08/2013. Recomendado para publicação em 30/09/2013 por Sandra Rolim Ensslin (Editora Científica). Publicado em 15/12/2013. 


\title{
Resumo
}

Este artigo analisa o processo de adequação dos métodos de reconhecimento de receita de incorporação imobiliária adotados no Brasil às normas internacionais de contabilidade IFRS. A pesquisa tem caráter descritivo, valendo-se de análise documental e de um caso real, por meio de simulação dos resultados das empresas da amostra pelos dois diferentes métodos de reconhecimento de receita, proporcionalmente à evolução da obra (POC), ou após sua conclusão; evidenciou-se que as variações observadas na receita e no lucro foram significativas. Porém, como todas as incorporadoras listadas no Novo Mercado da BM\&FBOVESPA aplicaram o método POC em 2010, a comparabilidade foi mantida no cenário nacional.

Palavras-chave: Receita de Incorporação Imobiliária. IFRS. POC. Comparabilidade.

\begin{abstract}
This article analyzes the adequacy process of recognition methods of real state construction revenue adopted in Brazil to the Accountancy International Standards IFRS. The study presents a descriptive approach by applying a documental analysis and a real case, through simulation of results at the sample companies by two different revenue recognition methods, proportionally to the improvement of construction (POC in Portuguese), or after its conclusion. The evidence emerged from this investigation was that the variations observed at the revenue and at the profits were significant. However, since all the construction developers listed at the New Market of BM\&FBOVESPA applied the POC method in 2010, the comparability was maintained on the national scenario.
\end{abstract}

Key words: Real State Construction Revenue. IFRS.POC. Comparability.

\section{Resumen}

En este artículo se analiza El proceso de adecuación de los métodos de reconocimiento de ingresos de bienesraícesen Brasil a las normas internacionales de contabilidad IFRS. La investigaciónes de tipo descriptivo, mediante análisis de documentos y de un caso real, a través de la simulación de resultados de empresas de la muestra por los dos métodos distintos de reconocimiento de ingresos en proporción al avance de la obra (POC), o después de su término. Se ha verificado que las variaciones observadas en los ingresos y en el lucro fueron significativas. Sin embargo, como todas las desarrolladoras relacionadas en el Novo Mercado de la BM\&FBOVESPA aplicaron el método POC en 2010, la comparación se mantuvo en el panorama nacional.

Palabras clave: Ingreso de Incorporación Inmobiliaria. IFRS. POC. Comparación. 


\title{
1 Introdução
}

Vivenciamos a crescente internacionalização da economia, com a expansão de companhias multinacionais e transnacionais, a prática de livre comércio, a expansão de blocos econômicos regionais, o aumento da demanda por recursos externos, e, principalmente, o rápido desenvolvimento do mercado de capitais e acelerado processo de integração das bolsas de valores mundiais.

Diante da nova dinâmica da economia mundial, as demonstrações financeiras das empresas são mais do que nunca as principais fontes de informação para a tomada de decisões e concretização dos negócios. Segundo Lopes e Martins (2007), "o mercado financeiro é um dos maiores usuários da informação contábil por intermédio de analistas [...]". (LOPES e MARTINS, 2007, p.9).

Dada essa relevância da informação contábil, a contabilidade precisa se adaptar, para compreender e registrar os efeitos dos novos negócios internacionais, e divulgar a situação econômica da empresa e seus resultados em uma linguagem universal, para atender as necessidades de informações de todos os usuários nacionais ou estrangeiros para tomada de decisão. A contabilidade, segundo Iudícibus (1997), pode ser conceituada como:

\begin{abstract}
O método de identificar, mensurar e comunicar informação econômica, financeira, física e social, a fim de permitir decisões e julgamentos adequados por parte dos usuários da informação. Este processo de comunicação implica o reconhecimento dos tipos de informação contábil e a avaliação da habilidade dos usuários em interpretar a informação adequadamente (IUDÍCIBUS, 1997, p.26).
\end{abstract}

Visando atender a essa necessidade, na comunidade européia foi criado em 1973 o IASC (International Accounting Standards Committee), a partir da união de órgãos contábeis de dez países: Alemanha, Austrália, Canadá, Estados Unidos, França, Irlanda, Japão, México, Países Baixos e Reino Unido. O IASC foi responsável pela emissão das normas internacionais de contabilidade (IAS). Em 2001, o comitê passou por uma reestruturação e resultou no IASB (International Accounting Standards Board), que passou a revisar as IAS, emitidas até então, e emitir novas normas, as IFRS (International Financial Reporting Standards), com objetivo de padronizar as demonstrações financeiras publicadas ao mercado. Os principais objetivos do IASB, conforme publicado no site oficial<http://www.ifrs.org>, são:

\begin{abstract}
Criar um conjunto único de normas compreensíveis, exequível, de alta qualidade, e globalmente aceitas, o International Financial Reporting Standard (IFRS), através do seu corpo normativo, o IASB, a fim de promover o uso e a aplicação rigorosa dessas normas, considerando também as necessidades de relatórios financeiros das economias emergentes e em pequenas e médias empresas (PME), e de alcançar a convergência das normas contábeis nacionais e adoção das IFRS como a melhor solução (Fonte < http://www.ifrs.org >).
\end{abstract}

A adoção desse modelo implica, então, um maior grau de transparência e confiabilidade das informações publicadas pelas empresas, o que permite aos usuários comparações, interpretações e análises para tomada de decisão de modo a mitigar os riscos das operações. A Comissão Européia foi pioneira na adoção das normas internacionais de contabilidade para preparação das demonstrações financeiras das empresas de capital aberto. "Rapidamente, a comunidade internacional vem reconhecendo os benefícios em adotar um 
conjunto de normas contábeis preparado sob a IASB e oficialmente aceito pela comunidade européia. [...] Hoje, mais de 100 países já adotam o IFRS como padrão contábil." (ERNST\&YOUNG; FIPECAFI, 2009, p.xxi).

É importante salientar que os termos "padronização" e "harmonização contábil" não podem ser empregados como sinônimos, visto que "padronização e harmonização diferem essencialmente por sua finalidade, a primeira busca 'uniformizar' e a segunda 'aproximar'" (WEFFORT, 2005, p. 62).

Para o Brasil, foi estratégico aderir às Normas Internacionais de Contabilidade, para penetrar no cenário mundial. $\mathrm{O}$ sucesso no processo de convergência às IFRS tende a aumentar a participação das empresas brasileiras nos negócios internacionais, e proporcionar o desenvolvimento e a integração supranacional de mercados de capitais e atrair investidores estrangeiros, o que confirma maior maturidade econômica do Brasil perante o mercado.

Porém, para as empresas brasileiras, que seguiam uma contabilidade regrada e estritamente formal, a adoção do modelo contábil internacional baseado em princípios, que consideram a essência das operações econômicas, tem sido um grande desafio. As IFRS são subjetivas, os profissionais de contabilidade precisam ter visão holística do negócio para realizar julgamentos e decidir a melhor forma de aplicação das normas internacionais de modo a refletir a realidade econômica da empresa, o que exige esforços não só da área financeira, mas também de áreas técnicas da companhia.

Assim, no processo de convergência total às Normas Internacionais de Contabilidade no Brasil, já era esperado o surgimento de dúvidas, questionamentos e discussões por parte dos profissionais de contabilidade, auditores, empresas, acadêmicos e outros grupos interessados.

No caso das empresas que atuam no setor de Incorporação Imobiliária, que motivou este trabalho, a publicação pelo Comitê de Pronunciamentos Contábeis dos Pronunciamentos Técnicos "Contratos de Construção" (CPC 17), "Receitas" (CPC 30), e da Interpretação Técnica "Contrato de Construção do Setor Imobiliário" (ICPC 02) despertou grande dúvida acerca das normas e práticas contábeis que deveriam ser adotadas para o reconhecimento de receita de incorporação imobiliária diante da possibilidade de diferentes interpretações dos pronunciamentos.

A interpretação que prevaleceu, em um primeiro momento, foi que, para seguir o padrão contábil internacional IFRS (obrigatório no Brasil a partir de 2010), as incorporadoras deveriam reconhecer a receita de um empreendimento apenas após a conclusão da obra, ou seja, no momento da entrega das chaves do imóvel ao cliente; e não de acordo com a evolução da obra (método conhecido como POC - percentage of completion), como era praticado pelas incorporadoras brasileiras de acordo com a legislação contábil brasileira até 2009. Porém, as empresas do setor não concordaram que deveriam alterar o método de reconhecimento de receita para estar em conformidade com as normas internacionais.

A discussão quanto à adequação das empresas de incorporação imobiliária brasileiras às normas internacionais IFRS dividiu opiniões e envolveu todos os órgãos competentes, como: CPC (Comitê de Pronunciamentos Contábeis), CFC (Conselho Federal de Contabilidade), FIPECAFI (Fundação Instituto de Pesquisas Contábeis, Atuariais e Financeiras), IASB (International Accounting Standards Board), CVM (Comissão de Valores Mobiliários), ABRASCA (Associação Brasileira das Companhias Abertas) e IBRACON (Instituto dos Auditores Independentes do Brasil).

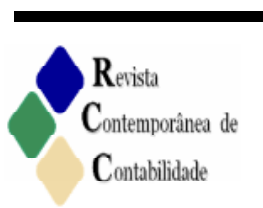

ISSN 2175-8069, UFSC, Florianópolis, v. 10, n. 21, p. 03-24, set./dez. 2013 
A questão que divide opiniões é: se os contratos de promessa de compra e venda de imóveis no Brasil se caracterizam como venda de um bem (CPC 30) ou como prestação de serviço por meio de contrato de construção (CPC 17).

A interpretação técnica ICPC 02 esclarece que, para o julgamento, nesses casos, é preciso identificar os riscos e benefícios a que estão expostas as empresas, os clientes e quem detêm o controle da unidade imobiliária; e o reconhecimento de receita se dará dependendo do momento em que esses "riscos", "benefícios" e "controle" são transferidos aos clientes.

Se o controle, riscos e benefícios forem continuamente transferidos de acordo com a evolução da obra, os contratos devem ser considerados contratos de construção, permanecendo assim o reconhecimento de receita pelo POC; já nos casos em que a transferência ocorre somente após a conclusão do empreendimento, o reconhecimento da receita deve ocorrer somente no momento da entrega das chaves.

Considerando essas análises e julgamentos como fundamentais para atingir o objetivo da padronização e garantir a utilidade das informações contábeis, surge o questionamento: a possibilidade de as empresas de incorporação imobiliária brasileiras adotarem métodos diferentes de reconhecimento de receita compromete a comparabilidade entre as demonstrações financeiras dessas empresas, fornecidas ao mercado?

O objetivo deste trabalho é, então, discutir os métodos de reconhecimento de receita adotados pelas entidades de incorporação imobiliária de capital aberto no mercado brasileiro e avaliar de que forma isso pode afetar a comparabilidade entre os resultados publicados a mercado dessas empresas.

Pretende-se atingir esse objetivo com duas análises principais: a consulta às demonstrações financeiras das entidades de incorporação imobiliária de capital aberto, a fim de identificar quais foram os métodos de reconhecimento de receita utilizados; e uma simulação do resultado considerando a alteração do método de reconhecimento de receita da empresa, no intuito de apontar as principais variações e os impactos.

Assim, a primeira hipótese (a ser testada na primeira análise) é a de que a evidenciação dos métodos de reconhecimento de receita, bem como das políticas contábeis adotadas, é suficiente para restabelecer a comparabilidade entre as demonstrações financeiras das incorporadoras que optaram por métodos diferentes. Considerando que:

Os relatórios financeiros, preparados e apresentados em conformidade com as normas internacionais IFRS, requerem declaração explicita e sem reservas, de aderência e conformidade com estas. Tal declaração implica afirmar que as informações foram preparadas e estão sendo apresentadas e divulgadas consoantes aos requisitos e exigências de todas as normas e interpretações técnicas que compõem o conjunto de normas IFRS. Além das questões inerentes ao nível de complexidade das normas internacionais IFRS, a divulgação necessária para atender a todos os requisitos de cada demanda que os profissionais responsáveis pelo processo de preparação estejam alinhados com todos estes requisitos (SANTOS, 2006, p. 189).

A segunda hipótese (a ser testada na segunda análise) é a de que a alteração do método de reconhecimento de receita de incorporação imobiliária causaria variações significativas nos valores de receita e do lucro, bem como no índice de margem de lucro, de modo a impedir uma análise comparativa entre empresas que optarem por métodos diferentes de reconhecimento da receita. A análise desses valores é relevante uma vez que: 


\begin{abstract}
A apuração do lucro líquido depende da contraposição entre receitas e despesas de uma entidade em um determinado período [...] o reconhecimento de receita é um fator chave para a adequada mensuração do desempenho de uma empresa. Normalmente, o item individual de maior relevância nas demonstrações financeiras é a receita. Investidores analisam índices / múltiplos que são calculados com base na receita. Modelos de crédito são alimentados por números baseados na receita. Nesse sentido, as definições para reconhecimento de receitas e as formas de determinação do seu valor são extremamente importantes na medida em que impactam fortemente o resultado e a análise das empresas (ERNST \& YOUNG; FIPECAFI, 2009, p. 157).
\end{abstract}

O trabalho de pesquisa que se segue expõe as normas internacionais de contabilidade (IFRS) e suas interpretações técnicas que dividem opiniões relacionadas ao reconhecimento de receita das empresas de incorporação imobiliária, bem como os argumentos apresentados pelas partes interessadas e órgãos competentes. Apresenta, ainda, os resultados de trabalhos já realizados na mesma linha de pesquisa, para fins de complemento e/ou confronto.

Com este trabalho, espera-se contribuir para um melhor entendimento do tema proposto por meio de revisão bibliográfica, da coleta de dados, análise documental, testes quantitativos e análise dos resultados, expondo a metodologia adotada para obter os resultados e conclusões.

\title{
2 Referencial Teórico
}

Para a elaboração deste trabalho, inicialmente, foi feito um entendimento das normas internacionais de contabilidade por meio da análise dos pronunciamentos técnicos, relacionados ao tema reconhecimento de receita de incorporação imobiliária, publicados pelo Comitê de Pronunciamentos Contábeis (CPC) no Brasil.

Destaca-se, então, o CPC 30 - Receitas, que trata do reconhecimento de receita de venda de bens, prestação de serviços, juros, royalties e dividendos. Considerando o termo Receita, conforme o Pronunciamento Conceitual Básico, "como aumento nos benefícios econômicos durante o período sob a forma de entrada de recursos ou aumento de ativos ou diminuição de passivos que resultam em aumentos do patrimônio líquido da entidade e não sejam provenientes de aporte de capital."

O objetivo principal do CPC 30 é determinar o momento em que a entidade deve reconhecer receita e estabelecer também critérios diferenciados de reconhecimento de receita para cada tipo de transação.

No caso da receita auferida na venda de bens, essa deve ser reconhecida pela empresa quando transferir ao comprador os riscos, benefícios e controle significativos decorrentes da propriedade. Já no caso de prestação de serviço, a receita deve ser reconhecida de forma proporcional aos serviços executados até o período do balanço referente, desde que possa ser confiavelmente mensurada.

O CPC 17 - Contratos de Construção expõe a definição de contrato de construção, como sendo um contrato de prestação de serviço diretamente relacionado à construção de ativo. Estabelece que para esses contratos, a contabilização das receitas, custos e despesas a eles relacionados devem ocorrer ao longo da execução da construção de acordo com sua evolução. Dessa forma, a receita reconhecida deve ser proporcional aos custos incorridos em cada período de acordo com medições físicas ou proporção de custos incorridos em relação aos custos orçados.



ISSN 2175-8069, UFSC, Florianópolis, v. 10, n. 21, p. 03-24, set./dez. 2013 
A interpretação técnica ICPC 02 - Contratos de Construção do Setor Imobiliário, elaborada a partir das normas internacionais (especificamente a interpretação IFRIC 15 Agreements for the Constructionof Real Estate) esclarece alguns dos vieses deixados pelos CPC 17 e CPC 30 partindo do pressuposto que possam existir as duas modalidades de contrato nas empresas de incorporação imobiliária: o de construção como prestação de serviço, ou contrato de compra e venda de bens, inclusive dentro de uma mesma empresa. Sendo assim, a sugestão para as empresas é, primeiramente, que façam a interpretação dos contratos firmados com os clientes, identificando a essência econômica da operação, e então optem pelo método de reconhecimento de receita mais adequado em cada operação.

A Orientação OCPC 01 - Entidades de incorporação imobiliária, adotada a partir de 2008 , tem como finalidade esclarecer as políticas contábeis que devem ser aplicadas pelas entidades de incorporação imobiliária, quanto às operações que, assim como a receita, também geraram dúvidas quanto ao seu registro contábil conforme IFRS. São elas: a formação do custo do imóvel, despesas comerciais como comissões, publicidade, estandes de vendas e apartamentos-modelo, permutas físicas, provisão para garantia, operações de cessão de recebíveis, ajuste a valor presente, e resultado de atualização monetária e juros.

Tais esclarecimentos não foram suficientes para dissolver a subjetividade das normas e, em 3 de dezembro de 2010, após mais uma série de estudos e discussões, o CPC emitiu a orientação OCPC 04 - Aplicação da Interpretação Técnica ICPC 02 às entidades de Incorporação Imobiliária brasileiras, aprovada pela Deliberação CVM n. 653, de 16 de dezembro de 2010, e pela Resolução CFC n. 1.317/10, de 9 de dezembro de 2010.

A orientação OCPC 04 - Aplicação da Interpretação Técnica ICPC 02 às entidades de Incorporação Imobiliária brasileiras foi elaborada para facilitar a tomada de decisão por parte das incorporadoras do Brasil quanto a qual dos dois métodos de reconhecimento de receita deveria ser adotado pela empresa para elaboração das suas demonstrações financeiras.

Para isso, foram analisadas as normas internacionais, os contratos de construção e expostos alguns exemplos reais e situações práticas comuns das entidades de incorporação imobiliária no Brasil. Concluiu-se a partir disso que, no ambiente econômico brasileiro, os contratos de construção podem ser considerados, em sua maioria, como contratos de prestação de serviço, justificando a manutenção do método de reconhecimento POC, de acordo com o CPC 17.

Um ponto fundamental dessa discussão refere-se à transferência dos riscos e benefícios sobre o imóvel em construção. O item 22 da OCPC 04 lista alguns exemplos de evidências de que esses riscos e benefícios são transferidos continuamente, como o fato de o contrato ter força de escritura pública, assegurando ao comprador todos os direitos de livre utilização do bem; a exigência de anuência da construtora caso o adquirente queira vender seu bem para terceiros e ainda não tenha concluído o pagamento integral do preço de aquisição, fato que acontece em qualquer transferência de devedor em outras situações; se o comprador tiver quitado o contrato, este poderá vendê-lo sem a necessidade de anuência do construtor; a legislação brasileira dá aos adquirentes o direito de trocar a construtora se esta estiver em atraso injustificado e não sanado superior a 30 dias em relação ao cronograma fixado; entre outros. O fato de os riscos e benefícios serem continuamente transferidos é um forte argumento ao reconhecimento de receitas ao longo da execução da obra.

A pesquisa realizada em 2011 sobre o mesmo assunto "Contabilidade no setor imobiliário residencial: Um estudo exploratório da visão dos impactos da convergência das 
normas brasileiras com normas internacionais", publicada no $8^{\circ}$ Congresso USP de Iniciação Científica em 2011, traz que:

Uma das principais teses que defendem a manutenção do reconhecimento por evolução de obra é a de que o mercado imobiliário brasileiro se diferencia de outros países por ter a figura do 'projeto na planta', onde os consumidores finais, buscando uma redução da concentração de pagamentos na aquisição, diluem o pagamento durante a sua obra. Portanto, estes se comprometeriam com o projeto e haveria a transferência de benefícios e riscos (CIA; CORNACHIONE JUNIOR, 2011, p. 14).

Porém, a classe dos auditores independentes, por exemplo, ainda defende que essa prática do método POC está em desacordo com as IFRS. O Ibracon expõe sua opinião contrária ao consenso publicado na OCPC 04 em seu Comunicado Técnico n. 05/2011:

É entendimento do Ibracon que, para atender aos preceitos da IFRIC 15 (ICPC 02), na elaboração das demonstrações contábeis em IFRS [...], as receitas e os custos das operações de incorporação imobiliária levadas a cabo no Brasil, consideradas eventuais exceções quando da análise de contratos específicos, devem ser registrados somente quando da entrega efetiva do imóvel, em geral, na "entrega das chaves", quando efetivamente ocorre a transferência para o promitente comprador e não de acordo com o andamento da obra (OCPC 04, 2011).

A CVM, por meio de Ofício-Circular n. 002/2011, orienta as auditorias independentes que as empresas de incorporação imobiliária que adotarem políticas contábeis de acordo com as conclusões da OCPC 04 terão atendido as normas internacionais. Assim, as auditorias não poderiam emitir relatório com ressalvas nesse aspecto.

As decisões ainda não são definitivas, o tema ainda está em discussão nos órgãos competentes que irão julgar se a OCPC 04 atende as normas internacionais de contabilidade. Caso o IASB exponha opinião contrária às práticas brasileiras, poderá solicitar a republicação das demonstrações financeiras das empresas de incorporação imobiliária no Brasil.

O International Accounting Standards Boars (IASB) e o Financial Accounting Standards Board (FASB), órgão normatizador das normas contábeis nos EUA, concluíram que a IAS 18 - Revenue e IAS 11- Construction Contracts expõem informações limitadas e de difícil entendimento e aplicação.

Sendo a Receita uma informação fundamental para análise das Demonstrações Financeiras e avaliação do desempenho de uma companhia ou setor, o IASB e o FASB se engajaram em um projeto de norma para esclarecer os princípios para reconhecimento de receita, desenvolvendo um padrão comum para reconhecimento de receitas entre IFRS e US GAAP.

Diante disso, no dia 14 de novembro de 2011, o IASB publicou em seu site $<$ www.ifrs.org > o Draft da nova norma sugerida Revenue from Contracts with Customers convidando o público interessado a comentar a proposta até 13 de março de 2012, e todos os comentários seriam considerados para realização de possíveis ajustes da norma internacional antes da publicação da versão final da IFRS, que de acordo com o calendário do IASB não será obrigatória a sua aplicação nas entidades antes de 2015. A norma Revenue from Contracts with Customers irá substituir a IAS 18 (CPC 30), a IAS 11 (CPC 17) e a IFRIC 15 (ICPC 02).

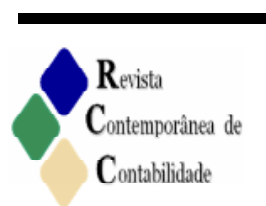

ISSN 2175-8069, UFSC, Florianópolis, v. 10, n. 21, p. 03-24, set./dez. 2013 
No dia 16 de novembro de 2011, o jornal Valor Econômico publicou a notícia "Audiência discute norma para receita", afirmando que a polêmica envolvendo o critério de reconhecimento de receita das incorporadoras imobiliárias brasileiras estaria bem perto de ter uma solução definitiva.

Procurado pela equipe do jornal, Alexsandro Broedel, então diretor da Comissão de Valores Mobiliários (CVM), disse: "não tenho dúvida de que a nova redação resolve a questão das incorporadoras, de que há transferência continuada nos contratos usados no Brasil. A leitura da norma não permite outra interpretação". O Instituto dos Auditores Independentes do Brasil (IBRACON) também foi procurado pela equipe do jornal, mas não se posicionou, afirmando que ainda estaria analisando a nova proposta do IASB.

O objetivo principal do IASB é concretizar um padrão contábil internacional e emitir normas contábeis que garantam a transparência e comparabilidade das demonstrações financeiras publicadas ao mercado.

A comparabilidade é considerada na estrutura conceitual básica uma das características qualitativas, assim como confiabilidade, compreensibilidade e relevância, e que determinam a utilidade das informações contidas nas demonstrações financeiras. O conceito de comparabilidade, conforme pronunciamento conceitual básico, é definido da seguinte forma:

\begin{abstract}
39. Os usuários devem poder comparar as demonstrações contábeis de uma entidade ao longo do tempo, a fim de identificar tendências na sua posição patrimonial e financeira e no seu desempenho. Os usuários devem também ser capazes de comparar as demonstrações contábeis de diferentes entidades a fim de avaliar, em termos relativos, a sua posição patrimonial e financeira, o desempenho e as mutações na posição financeira. Consequentemente, a mensuração e apresentação dos efeitos financeiros de transações semelhantes e outros eventos devem ser feitas de modo consistente pela entidade, ao longo dos diversos períodos, e também por entidades diferentes (IASB, 2011).
\end{abstract}

Na reportagem: "Interpretação de contratos afeta o setor imobiliário", publicada pelo Jornal Valor Econômico, em 31 de maio de 2011, foi descrito como ocorria a apuração do resultado na atividade de incorporação imobiliária brasileira antes da convergência ao IFRS. Antes de 2003, era apurado com base na receita recebida em relação ao valor total da venda, sendo os custos apropriados com base nessa mesma proporção. Marcelo Lico, diretor da Macro Auditoria e Consultoria, diz que nessa época, o resultado a apropriar era registrado no Grupo de Resultado de Exercícios Futuros (passivo), e tratava-se de uma prática contábil para atender à legislação fiscal, mas que feria um dos princípios mais importantes:o regime de competência.Com a publicação da Resolução do CFC n. 963 de 2003, a prática contábil foi alterada, e o reconhecimento de resultado passou a ser feito com base na produção ou andamento da obra. Essa resolução foi revogada a partir de 2010 em função do IFRS.

A preocupação dos investidores e analistas de mercado é a geração de caixa das construtoras. Mas o lucro contábil publicado, obtido pelo método POC, podem dificultar as análises, pois normalmente não acompanha o mesmo ciclo do fluxo de caixa. Segundo reportagem do Jornal Valor Econômico "Investidores estão de olho no caixa das construtoras", publicada no dia 18 de maio de 2011, o lucro contábil apontado nos balanços das incorporadoras não representa geração de caixa, pois os recursos só entram, de fato, após a entrega da obra, quando os clientes conseguirem o financiamento junto ao banco. Considerando o acelerado crescimento do setor, e que o ciclo de construção é longo (pelo 
menos três anos), os gastos com construção e novos projetos superam os valores recebidos de empreendimentos vendidos anteriormente.

Analistas do banco de investimento CreditSuisse buscaram estimar como que a transição das práticas contábeis brasileiras para as internacionais poderia impactar as demonstrações financeiras das incorporadoras. Assim, para as sete maiores empresas do setor foram feitas as simulações das demonstrações financeiras para o ano de 2010, considerando os dois diferentes métodos de reconhecimento de receita de incorporação. Os cálculos foram realizados com base na expectativa das empresas para os resultados de 2010 .

Comparando os resultados obtidos, evidenciou-se que todas as empresas perceberiam o impacto, pois, em média, a queda do lucro líquido foi de $43 \%$, e a queda no patrimônio líquido, de $25 \%$.

A pesquisa "Recognising revenue from the constrution of real estate em financial statements of developers in Poland", de Renata Dylag e Malgorzata Kucharczyk, publicada em 2011 no v. 10 da Accounting and Management Information Systems investigou se a introdução da interpretação IFRIC 15 teria um efeito significativo nas entidades de incorporação imobiliária da Polônia na contabilização dos contratos de construção.

A contabilidade da Polônia tem sofrido mudanças significativas para se aproximar do IFRS. Lá, foi emitida a Norma de Contabilidades Nacional 3 - Contratos de Construção (NAS 3 - Unfinished Construction Services) para entidades de incorporação imobiliária. Considerando que a Polônia é parte da União Européia, de acordo com art. $4^{\mathrm{o}}$ do Regulamento 1606/2002 do Parlamento Europeu e do Conselho de 19 de Julho de 2002, que trata da aplicação de Normas Internacionais de Contabilidade, as empresas que possuírem valores mobiliários negociados em mercados regulamentados de qualquer país membro ficam obrigadas a preparar as suas demonstrações financeiras consolidadas em conformidade com as IAS / IFRS. O posicionamento exposto quanto aplicação da interpretação IFRIC 15 é:

\begin{abstract}
Aplicando a NAS3 as empresas poderiam reconhecer receitas, custos e resultados associados à execução dos contratos de incorporação imobiliária, enquanto tais contratos estão em andamento. No entanto, as normas polonesas, da mesma forma como a Interpretação IFRIC 15, não deixam dúvidas de que a norma discutida não é aplicável aos serviços de construção civil realizados por incorporadoras imobiliárias, com objetivo de vender ou alugar o imóvel. Na legislação polaca a atividade dessas empresas consiste na construção e venda de apartamentos que é tratada pela contabilidade e efeitos fiscais, como uma atividade de produção. Portanto, a receita de uma incorporadora é a receita da venda de uma casa ou um apartamento, constituindo o produto das atividades de incorporação. A venda de uma casa ou um apartamento é acompanhada pela venda de seus terrenos, que no momento da compra são registados na contabilidade como bens. Assim, a receita de uma entidade de incorporação imobiliária é principalmente gerada pela venda de produtos e venda de bens (IFRIC 15).
\end{abstract}

A pesquisa analisou as demonstrações financeiras publicadas em 31 de dezembro de 2008 e 30 de junho de 2009 das empresas de incorporação imobiliária listadas na bolsa de Varsóvia. Dentre as 17 empresas analisadas, 67\% (12 empresas) apresentaram suas demonstrações financeiras reconhecendo receita de acordo com a IAS 18 , e apenas $23 \%$ (5 empresas) reconheceram receita de acordo com a IAS 11. Das cinco empresas que ainda reconheceram receita pelo método $\mathrm{POC}$, todas declararam que para as próximas publicações iriam mudar suas políticas contábeis para reconhecimento de receita de incorporação imobiliária pela IAS 18. 
A pesquisa concluiu que a mudança mais significativa percebida foi a postergação do reconhecimento das receitas pelas entidades de incorporação imobiliária, quando aplicada a IFRIC 15.

Não se tem conhecimento de outras pesquisas internacionais recentes a respeito desse tema, já que a adoção da IFRIC 15 data de 2009. Porém, antes disso, já havia pesquisas que abordassem esse tema. Eccles e Holt (2001) compararam as normas britânicas com as internacionais em relação aos impactos contábeis para o setor de construção. $\mathrm{Na}$ época, as normas internacionais estavam em vias de serem adotadas na União Européia e o debate já existia. Já Eccles et al (2005) entrevistaram contadores de 25 empresas de construção do Reino Unido a respeito do reconhecimento de receitas desse tipo de atividade e identificaram inconsistências entre as políticas contábeis, além de opiniões divergentes a respeito. Isso já ilustrava a necessidade de uma norma específica para esse assunto.

A partir do entendimento das normas internacionais e suas possíveis interpretações e aplicações, complementarmente aos conceitos e princípios contábeis, desenvolve-se este trabalho de pesquisa. Também foram consideradas as publicações e declarações das entidades envolvidas, as notícias que circularam na mídia e os resultados obtidos com pesquisas e trabalhos anteriormente publicados referentes ao tema.

\section{Metodologia da Pesquisa}

Após delimitação do tema, do problema de pesquisa, formulação de hipóteses, exposição dos objetivos e das justificativas, é necessário traçar um plano para operacionalizar o desenvolvimento da pesquisa. Kerlinger (1980, p. 94), citado por Beuren (2010, p. 76), explicita que "a palavra delineamento focaliza a maneira pela qual um problema de pesquisa é concebido e colocado em uma estrutura que se torna um guia para experimentação, coleta de dados e análise."

A pesquisa que se segue possui caráter descritivo, tendo como objetivo "a descrição das características de determinada população ou fenômeno, estabelecendo relações entre as variáveis." Silva (2003, p. 65) entende que "neste contexto, descrever significa identificar, relatar, comparar, entre outros aspectos."

Para operacionalizar a pesquisa, é fundamental definir criteriosamente a amostra para análise. Para investigação da primeira hipótese desse estudo, são contempladas todas as empresas de incorporação imobiliária brasileiras do Novo Mercado em 2010, segundo a listagem da BM\&FBOVESPA, disponível no site <https://www.bmfbovespa.com.br>. Ou seja, 16 empresas formam a amostra, conforme o Quadro 1.

Para essas empresas da amostra, a análise documental é feita por meio das suas respectivas demonstrações financeiras do exercício findo em 2010 publicados ao mercado. Tais demonstrações foram extraídas do site da Comissão de Valores Mobiliários (CVM) $<$ www.cvm.gov.br $>$.

Já, para investigar a segunda hipótese levantada, é utilizada a metodologia de análise a partir de um caso real, uma vez que, para simular o reconhecimento e apropriação de receita pelo método de entrega das chaves, são necessárias informações gerenciais que não são públicas. A empresa objeto de estudo é mantida em sigilo e tratada durante todo o trabalho pelo nome fictício "Incorporadora S.A". 
Quadro 1 - Relação de Empresas de Construção Civil listadas no Novo Mercado da Bovespa SEGMENTO CONSTRUÇAOO CIVIL

\begin{tabular}{|c|c|c|}
\hline RAZÃO SOCIAL & $\begin{array}{l}\text { NOME DE } \\
\text { PREGÃO }\end{array}$ & $\begin{array}{c}\text { CÓDIGO } \\
\text { NEGOCIAÇÃO }\end{array}$ \\
\hline 1 BROOKFIELD INCORPORAÇÕES S.A. & BROOKFIELD & BISA \\
\hline 2 CR2 EMPREENDIMENTOS IMOBILIARIOS S.A. & CR2 & CRDE \\
\hline 3 CYRELA BRAZIL REALTY S.A. EMPREEND E PART & CYRELA REALT & CYRE \\
\hline 4 DIRECIONAL ENGENHARIA S.A. & DIRECIONAL & DIRR \\
\hline 5 EVEN CONSTRUTORA E INCORPORADORA S.A. & EVEN & EVEN \\
\hline 6 EZ TEC EMPREEND. E PARTICIPAÇOES S.A. & EZTEC & EZTC \\
\hline 7 GAFISA S.A. & GAFISA & GFSA \\
\hline 8 HELBOR EMPREENDIMENTOS S.A. & HELBOR & HBOR \\
\hline 9 INPAR S.A. & INPAR S/A & INPR \\
\hline 10 JHSF PARTICIPAÇOES S.A. & JHSF PART & JHSF \\
\hline 11 MRV ENGENHARIA E PARTICIPAÇOES S.A. & MRV & MRVE \\
\hline 12 PDG REALTY S.A. EMPREEND E PARTICIPAÇOES & PDG REALT & PDGR \\
\hline 13 RODOBENS NEGOCIOS IMOBILIARIOS S.A. & RODOBENSIMOB & RDNI \\
\hline 14 ROSSI RESIDENCIAL S.A. & ROSSIRESID & RSID \\
\hline 15 TECNISA S.A. & TECNISA & TCSA \\
\hline 16 TRISUL S.A. & TRISUL & TRIS \\
\hline
\end{tabular}

Fonte: BM\&FBOVESPA (2013).

Adotar essa metodologia, nesta pesquisa, torna-se relevante, visto que permitirá conhecer melhor as principais características do setor e das incorporadoras imobiliárias, de modo a permitir uma descrição mais ampla e profunda do tema em questão, que contribuirá para as conclusões.

Para verificar a primeira hipótese, investiga-se por meio das Notas Explicativas e Relatório dos Auditores Independentes publicados referentes ao exercício de 2010, se a evidenciação das políticas contábeis adotadas foi adequada para as dezessete empresas da amostra.

Segundo Silva e Grigolo (2002), citado por Beuren (2010):

[...] a pesquisa documental vale-se de materiais que ainda não receberam nenhuma análise aprofundada. Esse tipo de pesquisa visa, assim, selecionar, tratar e interpretar a informação bruta, buscando extrair dela algum valor [...]. A utilização de pesquisa documental no sentido de organizar informações que se encontram dispersas [...] (SILVA e GRIGOLO apud BEUREN, 2010, p. 90).

Assim, facilitará a interpretação e julgamento do grau de evidenciação das notas explicativas de cada empresa.

Já para verificar a segunda hipótese, será apresentada uma estimativa dos resultados financeiros da empresa Incorporadora S.A., objeto do estudo, de 2010 simulando a adoção do CPC 30, ou seja, do método de reconhecimento de receita de incorporação de uma única vez, no evento de entrega das chaves aos clientes. Essa conversão será possível a partir das demonstrações financeiras fornecidas pela empresa juntamente com dados e informações gerenciais relevantes. Com o objetivo de esclarecer a segunda hipótese levantada, é feita uma comparação entre os resultados obtidos pelo CPC 17 e pelo CPC 30, analisando as principais variações evidenciadas, suas causas e seus efeitos.

Os resultados obtidos por meio da investigação e testes são apresentados neste trabalho de forma clara e objetiva, bem como as suas respectivas análises, de forma a sustentar a conclusão a cerca da problemática e hipóteses levantadas.

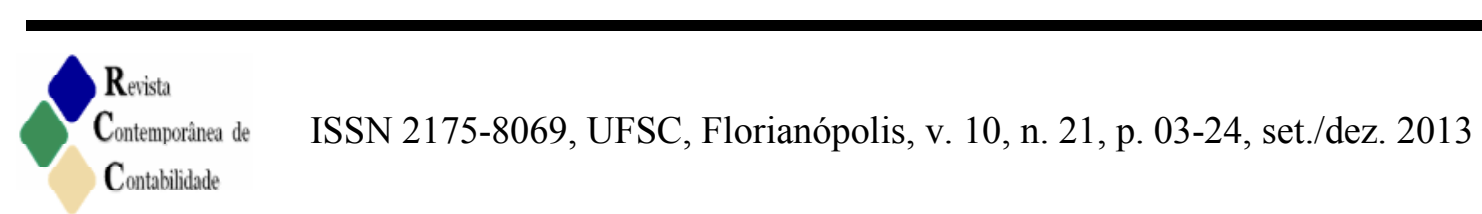




\section{Análise dos Resultados da Pesquisa}

\subsection{Evidenciação}

A partir das Demonstrações Financeiras Padronizadas (DFPs) e notas explicativas de 2010 publicadas pelas dezesseis empresas de incorporação imobiliária, abrangidas pela amostra, foi analisado se haviam declarado que as DFPs estavam em conformidade com as IFRS. E, de forma complementar, foi analisada a opinião dos Auditores Independentes quanto essa conformidade. No Quadro 2, abaixo, é apresentado um resumo das análises:

Quadro 2 - Resumo do resultado das análises das DFPs de 2010 para amostra

\begin{tabular}{|c|c|c|c|c|c|c|}
\hline \multirow{2}{*}{\multicolumn{2}{|c|}{$\begin{array}{l}\text { EMPRESAS DE } \\
\text { INCORPORAÇÃO } \\
\text { IMOBILIÁRIA }\end{array}$}} & \multicolumn{2}{|c|}{ NOTAS EXPLICATIVAS } & \multicolumn{3}{|c|}{ OPINIÃO DOS AUDITORES } \\
\hline & & $\begin{array}{l}\text { DFP } 2010 \\
\text { CONFORME } \\
\text { IFRS? }\end{array}$ & $\begin{array}{l}\text { RECEITA } \\
\text { POC ou } \\
\text { Chaves? }\end{array}$ & AUDITORIA INDEPENDENTE & $\begin{array}{c}\text { COM } \\
\text { RESSALVA? }\end{array}$ & $\begin{array}{c}\text { COM } \\
\text { ÊNFASE? }\end{array}$ \\
\hline 1 & BROOKFELD & SIM & POC & Deloitte & $\mathrm{NÃO}$ & SIM \\
\hline 2 & CR2 & SIM & $\mathrm{POC}$ & Grant Tornton & $\mathrm{NÃO}$ & SIM \\
\hline 3 & CYRELA REALT & SIM & $\mathrm{POC}$ & Ernst \& Young Terco & $\mathrm{NÃO}$ & SIM \\
\hline 4 & DIRECIONAL & SIM & $\mathrm{POC}$ & Ernst \& Young Terco & $\mathrm{NÃO}$ & SIM \\
\hline 5 & EVEN & SIM & $\mathrm{POC}$ & PricewaterhouseCoopers & $\mathrm{NÃO}$ & SIM \\
\hline 6 & EZTEC & SIM & $\mathrm{POC}$ & Deloitte & $\mathrm{NÃO}$ & SIM \\
\hline 7 & GAFISA & SIM & $\mathrm{POC}$ & Ernst \& Young Terco & $\mathrm{NÃO}$ & SIM \\
\hline 8 & HELBOR & SIM & $\mathrm{POC}$ & Ernst \& Young Terco & $\mathrm{NÃO}$ & SIM \\
\hline 9 & INPAR S/A & SIM & $\mathrm{POC}$ & Ernst \& Young Terco & $\mathrm{NÃO}$ & SIM \\
\hline 10 & JHSF PART & SIM & $\mathrm{POC}$ & Ernst \& Young Terco & $\mathrm{NÃO}$ & SIM \\
\hline 11 & MRV & SIM & $\mathrm{POC}$ & Deloitte & $\mathrm{NÃO}$ & SIM \\
\hline 12 & PDG REALT & SIM & $\mathrm{POC}$ & Ernst \& Young Terco & $\mathrm{NÃO}$ & SIM \\
\hline 13 & RODOBENSIMOB & SIM & $\mathrm{POC}$ & Deloitte & $\mathrm{NÃO}$ & SIM \\
\hline 14 & ROSSI RESID & SIM & $\mathrm{POC}$ & Ernst \& Young Terco & $\mathrm{NÃO}$ & SIM \\
\hline 15 & TECNISA & SIM & $\mathrm{POC}$ & Ernst \& Young Terco & $\mathrm{NÃO}$ & SIM \\
\hline 16 & TRISUL & SIM & $\mathrm{POC}$ & Ernst \& Young Terco & $\mathrm{NÃO}$ & SIM \\
\hline
\end{tabular}

Fonte: Dados da pesquisa.

Conforme quadro acima, todas as empresas de incorporação imobiliária no Brasil declararam estar seguindo as normas internacionais do IFRS em 2010. E podemos notar também que todas as empresas evidenciaram em nota explicativa que mantiveram o método POC para o reconhecimento das receitas auferidas, adotando o CPC 17 - Contratos de Construção, estando de acordo, então, com a ICPC 02 e a OCPC 04.

Ao contrário do que evidenciamos no mercado brasileiro, a pesquisa realizada na Polônia, exposta anteriormente, evidenciou que empresas de incorporação imobiliária aplicaram métodos de reconhecimento de receitas diferentes, e, ainda, que a maioria delas optou por seguir a IAS 18 (CPC 30). Quanto à opinião dos Auditores Independentes, percebeu-se que nenhum parecer teve ressalva, ou seja, mesmo o IBRACON se declarando contrário ao que foi decidido e acordado na OCPC 04, os auditores respeitaram as orientações do Ofício-Circular n. 002/2011 da CVM. Porém, a fim de manifestarem sua opinião contrária, incluíram um parágrafo de ênfase no parecer destacando que o método de reconhecimento de receita pelo POC adotado pelas empresas brasileiras ainda não foi oficialmente aceito pelo IASB. Segue texto padrão do parágrafo de ênfase publicado: 
Conforme descrito na Nota $X$, as demonstrações financeiras individuais (controladora) e consolidadas foram elaboradas de acordo com as práticas contábeis adotadas no Brasil. As demonstrações financeiras consolidadas preparadas de acordo com as IFRS aplicáveis a entidades de incorporação imobiliária consideram adicionalmente a Orientação OCPC 04 editada pelo Comitê de Pronunciamentos Contábeis, que trata do reconhecimento da receita desse setor, conforme descrito em maiores detalhes na Nota Y. Determinados assuntos relacionados ao significado e aplicação do conceito de transferência contínua de riscos, benefícios e de controle na venda de unidades imobiliárias serão analisados pelo International Financial Reporting Interpretation Committee (IFRIC). Os resultados dessa análise podem fazer com que as incorporadoras imobiliárias tenham que revisar suas práticas contábeis relacionadas ao reconhecimento de receitas (CVM, Ofício-Circular n. 002/2011).

Procurou-se nas notas explicativas e relatório da administração se as empresas divulgaram informações que permitissem a conversão das DFPs para o método de reconhecimento de receita na entrega das chaves (CPC 30) para fins de comparação do resultado, porém como não é exigido pelas normas internacionais, não foram evidenciadas informações suficientes para essa análise. Faz-se, assim, necessária a análise de um caso real para testar a segunda hipótese.

Com isso, a avaliação das demonstrações financeiras dessas dezessete companhias demonstrou que o tratamento contábil para o reconhecimento de receitas foi absolutamente idêntico, já que todas utilizaram o POC e nenhuma delas teve ressalva no parecer dos auditores independentes.

Assim, a primeira hipótese, desenvolvida na introdução deste trabalho, não precisou ser testada, já que a expectativa inicial da pesquisa seria a de encontrar tratamento diverso entre as empresas, e o objetivo era o de avaliar se as notas explicativas auxiliariam (ou não) os usuários a restabelecer a comparabilidade entre as companhias.

\subsection{Análise do Caso Real da Incorporadora S.A.}

A Incorporadora S.A., objeto de estudo para a avaliação da segunda hipótese deste trabalho, é uma construtora com capital aberto que atua no setor de incorporação imobiliária brasileiro. Para a análise do caso na Incorporadora S.A., foi necessário entender o negócio da empresa, o que é incorporação imobiliária, e quais os processos envolvidos nessa atividade. A Incorporadora S.A. é composta por mais de 300 empresas, apresentando uma característica típica do setor de construção, em que a abertura de diversas empresas é feita para facilitar o controle e gerenciamento das obras em parcerias e para agilizar a aquisição do habite-se.

Então, para operacionalizar a análise a partir do caso na Incorporadora S.A. foram selecionadas as dez empresas que apresentaram as maiores receitas brutas de vendas em 2010, que somadas representavam $30 \%$ da receita bruta total do grupo reconhecida no período.

Foram extraídas todas as Demonstrações de Resultado do Exercício (DRE) individuais de 2010 das empresas selecionadas, que foram elaboradas de acordo com CPC 17. Para realizar a conversão dos resultados do exercício para o CPC 30, que prevê o reconhecimento de receita após a conclusão da obra na entrega das chaves, é fundamental conhecer a data de entrega dos empreendimentos (dos bens), condição considerada para reconhecimento da receita. A Tabela 1, a seguir, apresenta o cenário das empresas selecionadas, a quantidade de empreendimentos e respectivos prazos de entrega dos empreendimentos:

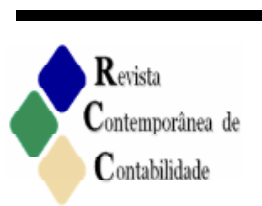

ISSN 2175-8069, UFSC, Florianópolis, v. 10, n. 21, p. 03-24, set./dez. 2013 
Tabela 1 - Análise dos empreendimentos das empresas objeto de estudo

\begin{tabular}{c|c|c|c|c}
\hline \multirow{2}{*}{ EMPRES A } & \multicolumn{5}{|c}{ EMPREENDIMENTOS } \\
\cline { 2 - 5 } & $\begin{array}{c}\text { Entrega antes } \\
\text { de 2010 }\end{array}$ & $\begin{array}{c}\text { Entrega em } \\
2010\end{array}$ & $\begin{array}{c}\text { Entrega após } \\
2010\end{array}$ & TOTAL \\
\hline 1 & 4 & 0 & 4 & 8 \\
\hline 2 & 1 & 2 & 0 & 3 \\
\hline 3 & 4 & 1 & 3 & 8 \\
\hline 4 & 1 & 0 & 2 & 3 \\
\hline 5 & 0 & 1 & 0 & 1 \\
\hline 6 & 0 & 0 & 2 & 2 \\
\hline 7 & 1 & 1 & 4 & 6 \\
\hline 8 & 0 & 0 & 2 & 2 \\
\hline 9 & 0 & 0 & 6 & 6 \\
\hline 10 & 0 & 0 & 1 & 1 \\
\hline TOTAL & 11 & 5 & 24 & 40 \\
\hline
\end{tabular}

Fonte: Dados da pesquisa.

A partir dessas informações, o procedimento adotado para simulação das DREs de acordo com o CPC 30 foi: (i) para os empreendimentos entregues em 2010, deve-se reconhecer a receita total dos empreendimentos, ou seja, acumular as receitas reconhecidas nos períodos anteriores e reconhecer a receita toda em uma única vez; (ii) para os empreendimentos entregues antes de 2010, deve-se manter os valores de receitas reconhecidos em 2010, pois os montantes apresentados são referentes à venda de unidades em estoque, que recebem o mesmo tratamento nos dois métodos de reconhecimento de receita; (iii) já para os empreendimentos que serão entregues após 2010, deve-se estornar as receitas reconhecidas, e anular o efeito no resultado.

Importante salientar que neste estudo foi desconsiderada a questão tributária para fins de simplificação das simulações e análises, visto que as empresas analisadas optam por diferentes regimes tributários e possuem empreendimentos afetados pelo RET (Regime especial de tributação).

Após as simulações realizadas, os efeitos da alteração de método de reconhecimento de receita bruta de vendas em 2010 nos valores de receita bruta foram evidenciados, conforme Gráfico 1 e Tabela 2.

Diante dos resultados apresentados, pode-se perceber que as empresas 6, 8, 9 e 10 apresentariam receitas brutas iguais a zero considerando o reconhecimento de receita pelo CPC 30, pois todos os empreendimentos dessas empresas serão entregues após 2010. E a empresa 1 apresentou uma redução da receita de aproximadamente $100 \%$, pois mesmo tendo quatro empreendimentos entregues antes de 2010, os estoques vendidos representavam quantidades e valores baixos.

Já as empresas 2 e 5 apresentaram receitas maiores pelo CPC 30 do que pelo CPC17, isso porque tiveram respectivamente, 2 e 1 empreendimentos entregues em 2010, e não precisam estornar nenhuma receita do exercício, pois não possuem empreendimentos que serão entregues após 2010, ou seja, acumularam as receitas reconhecidas em períodos anteriores. 
Gráfico 1- Análise das variações da Receita Bruta de 2010

Análise Receita Bruta de Vendas - 2010

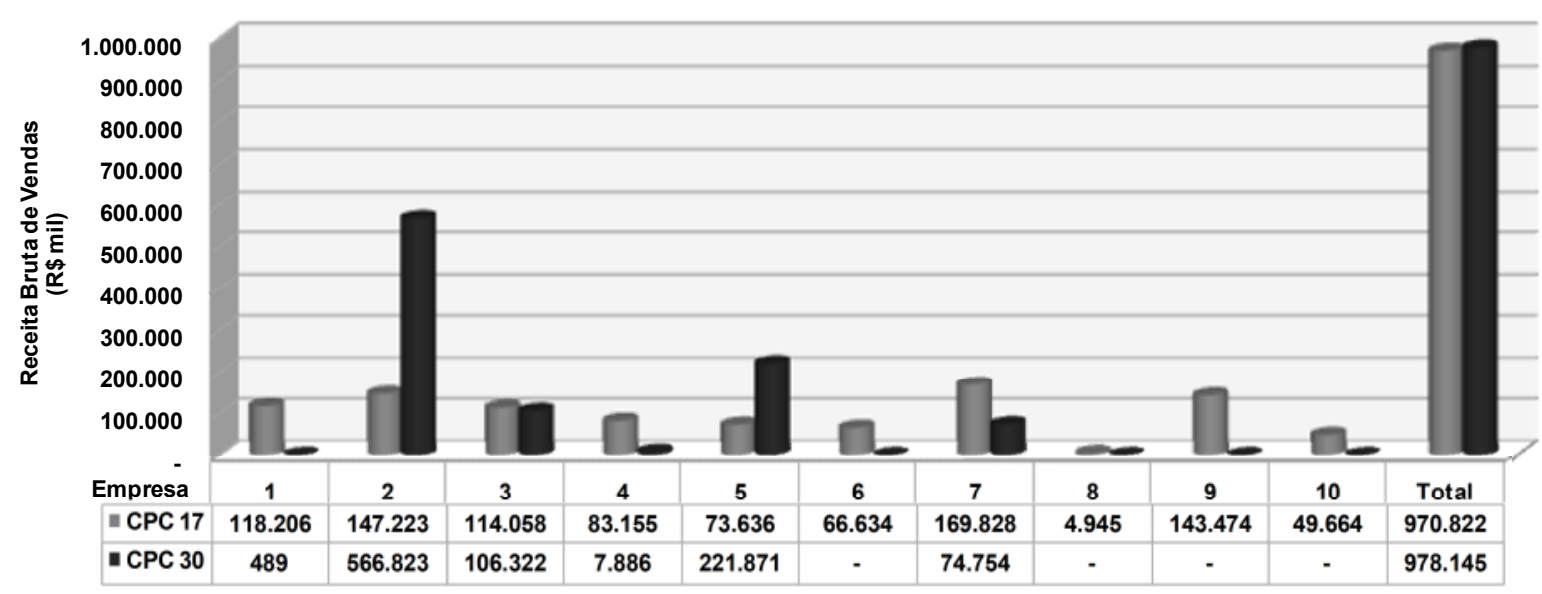

Fonte: Dados da pesquisa.

Tabela 2 - Análise das variações da Receita Bruta de 2010

\begin{tabular}{c|r|r|r|c}
\hline \multicolumn{5}{c|}{ Análise Receita Bruta de Vendas - 2010 } \\
\hline \multirow{2}{*}{ Empresa } & $\begin{array}{c}\text { CPC 17 } \\
\text { (R\$ mil) }\end{array}$ & $\begin{array}{c}\text { CPC 30 } \\
\text { (R\$ mil) }\end{array}$ & $\begin{array}{c}\text { Variação } \\
\text { Absoluta } \\
\text { (R\$ mil) }\end{array}$ & $\begin{array}{c}\text { Variação } \\
\text { (\%) }\end{array}$ \\
\hline $\mathbf{1}$ & 118.206 & 489 & $(117.717)$ & $-100 \%$ \\
\hline $\mathbf{2}$ & 147.223 & 566.823 & 419.600 & $285 \%$ \\
\hline $\mathbf{3}$ & 114.058 & 106.322 & $(7.736)$ & $-7 \%$ \\
\hline $\mathbf{4}$ & 83.155 & 7.886 & $(75.268)$ & $-91 \%$ \\
\hline $\mathbf{5}$ & 73.636 & 221.871 & 148.235 & $201 \%$ \\
\hline $\mathbf{6}$ & 66.634 & - & $(66.634)$ & $-100 \%$ \\
\hline $\mathbf{7}$ & 169.828 & 74.754 & $(95.074)$ & $-56 \%$ \\
\hline $\mathbf{8}$ & 4.945 & - & $(4.945)$ & $-100 \%$ \\
\hline $\mathbf{9}$ & 143.474 & - & $(143.474)$ & $-100 \%$ \\
\hline $\mathbf{1 0}$ & 49.664 & - & $(49.664)$ & $-100 \%$ \\
\hline Total & $\mathbf{9 7 0 . 8 2 2}$ & $\mathbf{9 7 8 . 1 4 5}$ & $\mathbf{7 . 3 2 3}$ & $\mathbf{1 \%}$ \\
\hline Fonte: Dados da pesquisa & & &
\end{tabular}

Fonte: Dados da pesquisa.

A empresa 3 teve uma variação de apenas 7\% demonstrando o efeito de compensação, apesar de estornar a receita de 3 empreendimentos que ainda não foram entregues, manteve a receita de 4 empreendimentos e reconheceu acumulada a receita de 1 . A empresa 4 manteve apenas $8 \%$ da sua receita referente às receitas de venda de unidades em estoque do empreendimento que foi entregue antes de 2010 e não teve nenhum entregue em 2010. E a empresa 7 reduziu 56\% sua receita, pois 4 de seus 6 empreendimentos serão entregues após 2010.

Nas análises individuais das variações de receita de cada empresa, de forma geral, verificamos grandes variações, e percebemos que não existe uma correlação entre as variações das empresas, ou uma proporcionalidade, e nem uma tendência de aumento ou queda, pois 
elas são determinadas pelo número de empreendimentos, datas de entrega das unidades, o valor de receita pretendida, entre outros.

Porém, se analisarmos a receita bruta total, verifica-se uma variação inexpressiva de apenas 1 no valor da receita bruta total dessa amostra. Ou seja, neste estudo, percebe-se o efeito da compensação entre as variações nas receitas brutas das empresas da amostra selecionada, o que permite concluir que o efeito da compensação é possível. Porém, conforme discutido por Yin (2010), especialmente a partir de um único caso, há uma dificuldade para fazer generalização para populações ou universos. Então, não podemos generalizar que sempre haverá uma compensação de forma a anular os efeitos das diferenças entre os métodos de reconhecimento de receita utilizados. Assim, não podemos afirmar que isso ocorreria se simulássemos as receitas brutas de vendas das demais empresas do grupo da Incorporadora S.A., nem para as demais incorporadoras.

Já para análise do Lucro Bruto de 2010 foi necessário o ajuste não só dos valores da receita bruta de vendas, mas também dos valores reconhecidos como custo de obra e comissões de vendas do período, pois, conforme a orientação OCPC 01 - Entidades de incorporação imobiliária, esses itens devem ser reconhecidos proporcionalmente aos valores de receitas de acordo com o método utilizado. Após as simulações realizadas, os efeitos evidenciados da mudança de método de reconhecimento de receita no Lucro antes do Imposto de Renda (LAIR) em 2010, foram apresentados no Gráfico 2 e Tabela 3.

Ao analisarmos os resultados obtidos após as simulações do LAIR das empresas da amostra, verificamos que as empresas 4, 6, 9 e 10 apresentariam prejuízos em 2010 utilizando o método de reconhecimento de receita na entrega das chaves. Isso ocorreu porque essas empresas reconheceriam receitas brutas, custos de obra e despesas com comissões de vendas iguais a zero, porém apresentaram valores de despesas comerciais, administrativas e financeiras em 2010 que são reconhecidas no resultado do exercício independente do reconhecimento de receita.

Gráfico 2- Análise das variações do LAIR de 2010

Análise Lucro Antes do IR - 2010

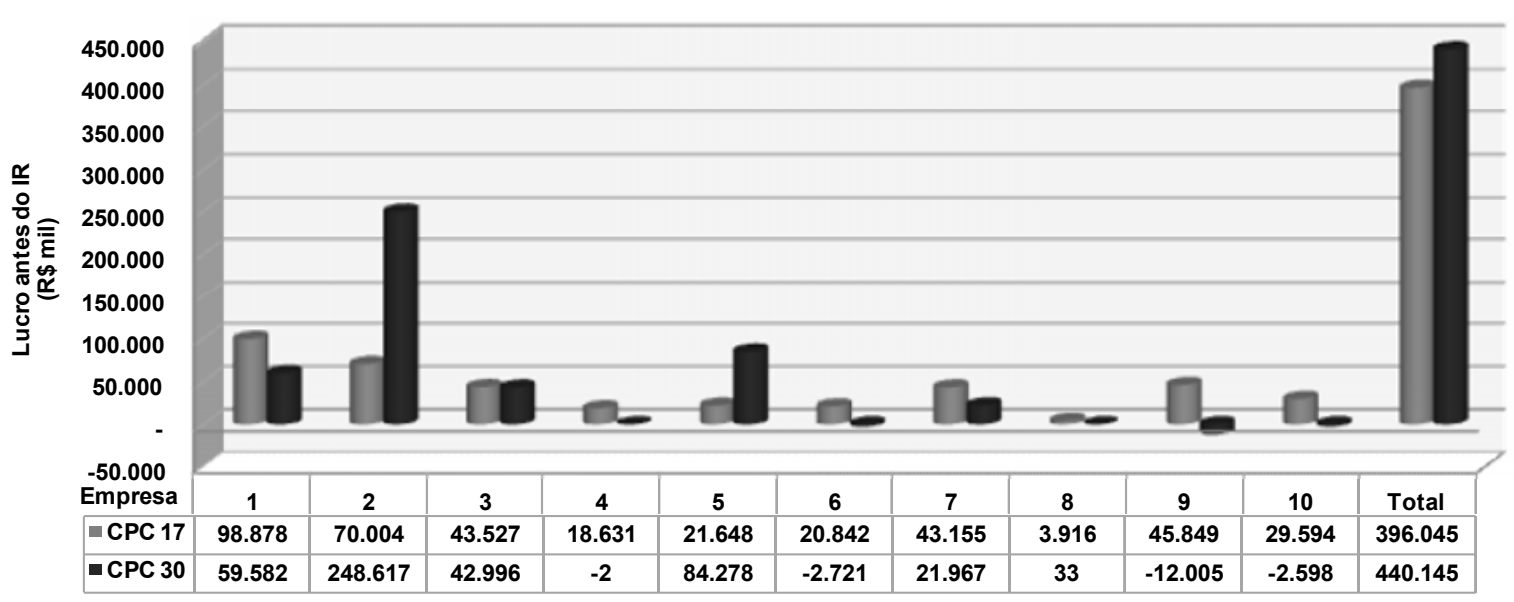

Fonte: Dados da pesquisa. 
Tabela 3 - Análise das variações do LAIR de 2010

\begin{tabular}{c|r|r|r|c}
\hline \multicolumn{5}{c|}{ Análise Lucro Antes do IR - 2010 } \\
\hline Empresa & $\begin{array}{c}\text { CPC 17 } \\
\text { (R\$ mil) }\end{array}$ & $\begin{array}{c}\text { CPC 30 } \\
\text { (R\$ mil) }\end{array}$ & $\begin{array}{c}\text { Variação } \\
\text { Absoluta } \\
\text { (R\$ mil) }\end{array}$ & $\begin{array}{c}\text { Variação } \\
\text { (\%) }\end{array}$ \\
\hline $\mathbf{1}$ & 98.878 & 59.582 & $(39.296)$ & $-40 \%$ \\
\hline $\mathbf{2}$ & 70.004 & 248.617 & 178.613 & $255 \%$ \\
\hline $\mathbf{3}$ & 43.527 & 42.996 & $(532)$ & $-1 \%$ \\
\hline $\mathbf{4}$ & 18.631 & $(2)$ & $(18.634)$ & $-100 \%$ \\
\hline $\mathbf{5}$ & 21.648 & 84.278 & 62.630 & $289 \%$ \\
\hline $\mathbf{6}$ & 20.842 & $(2.721)$ & $(23.563)$ & $-113 \%$ \\
\hline $\mathbf{7}$ & 43.155 & 21.967 & $(21.187)$ & $-49 \%$ \\
\hline $\mathbf{8}$ & 3.916 & 33 & $(3.883)$ & $-99 \%$ \\
\hline $\mathbf{9}$ & 45.849 & $(12.005)$ & $(57.854)$ & $-126 \%$ \\
\hline $\mathbf{1 0}$ & 29.594 & $(2.598)$ & $(32.192)$ & $-109 \%$ \\
\hline Total & $\mathbf{3 9 6 . 0 4 5}$ & $\mathbf{4 4 0 . 1 4 5}$ & $\mathbf{4 4 . 1 0 1}$ & $\mathbf{1 1 \%}$ \\
\hline
\end{tabular}

Fonte: Dados da pesquisa.

A empresa 1 apresentou uma redução de $40 \%$ do LAIR. Já as empresas 7 e 8 , a redução do lucro seguiu a proporção de redução das receitas. E a empresa 3 apresentou uma redução inexpressiva de 1\% no lucro, confirmando o efeito da compensação apresentado na análise anterior.

Apenas as empresas 2 e 5 apresentaram resultados maiores pelo CPC 30 do que pelo CPC 17 , em que o lucro aumentou, respectivamente, $255 \%$ e $289 \%$. Isso porque aumentaram substancialmente os valores reconhecidos de receita bruta de vendas no período, conforme descrito anteriormente, e mantiveram-se os valores referentes às despesas operacionais, exceto comissões de vendas.

De forma geral, o LAIR das empresas variou de um aumento de $289 \%$ a uma redução de $126 \%$, o que impossibilita a conclusão de uma variação esperada para as empresas que não fizeram parte deste estudo.

Porém, considerando o LAIR total da amostra em 2010 observamos que se as empresas tivessem reconhecido receita de acordo com o CPC 30 haveria um pequeno aumento de $11 \%$ no LAIR, ou seja, também ocorreria uma compensação significativa das variações individuais das dez empresas analisadas.

Sob a perspectiva da análise financeira de balanços e índices de rentabilidade, podemos analisar a margem de lucro, considerando o montante total do LAIR sobre o montante total de receita bruta em 2010, e verifica-se que reconhecendo a receita pelo CPC 17 a margem de lucro seria de $41 \%$, enquanto pelo CPC 30 seria de $45 \%$, apresentando uma pequena variação de 4 p.p., que não seria suficiente para distorcer uma análise.

Portanto, os resultados obtidos demonstram que, analisando cada empresa individualmente, a alteração do método de reconhecimento de receita traria significativa variação nos valores de receita e lucro das incorporadoras. Porém, quando os empreendimentos são tomados em conjunto e estão em estágios diferenciados, os efeitos contábeis acabam, de certo modo, compensando-se.

Ressalta-se novamente a impossibilidade de generalização dos resultados, pois essa simulação se aplica apenas ao caso em específico. 


\section{Considerações Finais}

De acordo com a Lei 11.638, a partir do exercício de 2010 as empresas brasileiras de capital aberto deveriam, obrigatoriamente, publicar seus resultados conforme as normas internacionais de contabilidade. Neste trabalho investigou-se, então, se as entidades de incorporação imobiliária adotaram o padrão contábil internacional, e verificou-se que todas declaram que suas demonstrações financeiras publicadas referentes ao exercício de 2010 foram elaboradas de acordo com as IFRS, estando, então, em conformidade com a Lei.

No caso das incorporadoras, elas deveriam divulgar também qual foi método de reconhecimento de receita de vendas adotado, e todas divulgaram que optaram por manter o método de reconhecimento de receita pelo POC, ou seja, reconheceram receita conforme o CPC 17 - Contratos de Construção, sustentadas pela Orientação OCPC 04 - Aplicação da Interpretação Técnica ICPC 02 às Entidades de Incorporação Imobiliária Brasileiras.

Como todas as incorporadoras da amostra analisada optaram por utilizar o mesmo método de reconhecimento de receita, conclui-se que os resultados de 2010 dessas podem ser comparados em si sem causar distorções nas análises financeiras.

Considerando a amostra das dez empresas analisadas da Incorporadora S.A., ao converter as suas Demonstrações dos Resultados do exercício de 2010, elaboradas seguindo o CPC 17 - Contratos de Construção, para o CPC 30 - Receitas evidenciaram-se, de forma geral, variações bastante significativas nos valores de receita brutas e lucro antes do imposto de renda (LAIR) de cada empresa. Já consolidando os valores de receita bruta e do LAIR das dez empresas, devido ao efeito da compensação, evidenciaram-se variações pequenas, que para a análise da margem de lucro, por exemplo, não causariam distorções relevantes.

Então, para essa análise, considerando as variações individuais das empresas, concluise que a aplicação dos dois diferentes métodos de reconhecimento de receita de incorporação imobiliária dificultaria as análises comparativas entre os resultados das empresas, porém considerando as variações totais do resultado, conclui-se que não modificaria significativamente as análises financeiras baseadas nas informações contábeis do resultado.

Porém, não se deve generalizar que os resultados obtidos nessa análise se confirmariam, também, para as demais empresas da Incorporadora S.A., ou ainda, para as outras empresas de incorporação imobiliária caso houvesse a conversão para o CPC 30, pois essas variações e compensações observadas dependem do perfil da empresa (grande porte, pequeno porte), do número de empreendimentos lançados, do prazo de entrega das obras, da receita pretendida, do cenário econômico entre outros fatores particulares de cada empresa.

O objetivo deste trabalho foi alcançado satisfatoriamente, pois foram obtidos respostas e argumentos capazes de sustentar as hipóteses levantadas para entender e esclarecer melhor o tema reconhecimento de receita nas empresas de incorporação imobiliária brasileiras.

O tema "reconhecimento de receitas" continua em pauta devido à sua relevância para análise das Demonstrações Financeiras e análise de desempenho das empresas. E a discussão quanto ao método mais adequado para reconhecimento de receita de incorporação imobiliária ainda não terminou, embora consideramos que, dadas as condições dos contratos e legislações existentes no Brasil, a OCPC 04 não contraria as normas internacionais de contabilidade.

Torna-se relevante neste momento, então, um estudo aprofundado da nova norma proposta no dia 14 de novembro de 2011 pelo IASB e pelo FASB para receita: Revenue from 
Contracts with Customers, que irá substituir a IAS 18 (CPC 30), a IAS 11 (CPC 17) e a IFRIC 15 (ICPC 02) que foram consideradas de difícil entendimento e aplicação. Investigando, por exemplo, as principais mudanças propostas, quais os possíveis reflexos em empresas brasileiras, os possíveis impactos no método de reconhecimento de receita de incorporação imobiliária, vai-se ao encontro da Orientação OCPC 04, entre outros aspectos.

\section{Referências}

BEUREN, Ilse Maria. Como Elaborar Trabalhos Monográficos em Contabilidade: Teoria e Prática. São Paulo: Atlas: 2010.

BOVESPA. Empresas de construção civil de incorporação imobiliária listadas no Novo Mercado. Disponível em: <http://www.bmfbovespa.com.br/cias-listadas/empresaslistadas/BuscaEmpresaListada.aspx?segmento=Constru $\% \mathrm{c} 3 \% \mathrm{a} 7 \% \mathrm{c} 3 \% \mathrm{a} 3 \mathrm{o}+$ Civil\&idioma=ptbr>. Acesso em: 23 de abr.2011.

CIA, Joanilia Neide de Sales. CORNACHIONE JUNIOR, Edgard Bruno. Contabilidade no setor imobiliário residencial: Um estudo exploratório da visão dos impactos da convergência das normas brasileiras com normas internacionais - IFRS para alguns segmentos de mercado. $8^{\circ}$ Congresso USP de Iniciação Científica, 2011. Disponível em:

$<$ http://www.congressousp.fipecafi.org/artigos112011/an_resumo.asp?con=2\&cod_trabalho= $335 \&$ titulo $=$ Contabilidade + no + setor + imobili $\%$ E1 rio + residencial $\% 3 \mathrm{~A}+\mathrm{Um}+$ estudo + explorat \%F3rio + da + vis $\% E 3 o+$ dos + impactos + da + conv $>$. Acesso em: 10 jun. 2011.

COMISSÃO DE VALORES MOBILIÁRIOS. Seção: Ofício-Circular. Ofício-Circular CVM/SNC/SEP n. 002/2011 de 4 de março de 2011. Disponível em:

$<$ http://www.cvm.gov.br/port/atos/oficios/Ofício\%20Circular\%20SEP\%20SNC\%2002\%2020 11\%20(reemissão).pdf>. Acesso em: 01 maio 2011.

COMITÊ DE PRONUNCIAMENTOS CONTÁBEIS. Seções: Pronunciamentos, Interpretações e Orientações Técnicas. Disponível em: <http://www.cpc.org.br/index.php>. Acesso em: 01 maio 2011.

CONSELHO FEDERAL DE CONTABILIDADE. Seção: Legislação. Resolução CFC n. 1005 de 7 de outubro de 2005. Disponível em:

$<$ http://www.cfc.org.br/sisweb/sre/detalhes_sre.aspx?Codigo=2005/001055 $>$.Acesso em: 01 maio2011.

CREDIT SUISSE. Brazilian homebuilders - Assessing the impact of IFRS accounting on the homebuilding sector. Disponível em: $<$ https://br.credit-

suisse.com/analise/empresas.aspx>. Acesso em: 20 out. 2010.

D’ AMBROSIO, Daniela; TORRES, Fernando. Investidores estão de olho no caixa das construtoras. Jornal Valor Econômico, 18/05/2011. Disponível em: 
$<$ http://www.valor.com.br/arquivo/888123/investidores-estao-de-olho-no-caixa-dasconstrutoras $>$. Acesso em: 14 jun. 2011.

DYLAG, Renata; KUCHARCZYK, Malgorzata. Recognising revenue from the constrution of real estate em financial statements of developers in Poland. Accounting and Management Information Systemstem, v.10, 2011.

ECCLES, Timothy; HOLT, Andrew.International accounting standards: a paradigm shift for corporate real estate. Journal of Corporate Real Estate.v.4, n.1, 2001, p.66-82.

ECCLES, Timothy; HOLT, Andrew; FELL-SMITH, Wesley. Revenue recognition and real estate companies: a preliminar analysis. Briefings in Real Estate Finance.v.4, n.3, 2005.

ERNST \& YOUNG; FIPECAFI. Manual de normas internacionais de contabilidade: IFRS versus normas brasileiras. 1.ed. São Paulo: Atlas, 2009.

FERREIRA, Angela. Interpretação de contratos afeta setor imobiliário. Jornal Valor Econômico, 31/05/2011. Disponível em:

$<$ http://www.valor.com.br/arquivo/890323/interpretacao-de-contratos-afeta-o-setorimobiliario>. Acesso em: 14 jun. 2011.

IBRACON. Comunicado Técnico Ibracon n 05.2011. Disponível em:

$<$ http://www.ibracon.com.br/ibracon/Portugues/detPublicacao.php?cod=184>. Acesso em: 01 maio. 2011.

IFRS. About the IFRS Foundation and the IASB. Disponível em:

$<$ http://www.ifrs.org/The+organisation/IASCF+and+IASB.htm>. Acesso em: 23 abr. 2011.

IFRS. Revised exposure draft and Comment letters. Disponível em:

$<$ http://www.ifrs.org/Current+Projects/IASB+Projects/Revenue+Recognition/EDNov11/ED.h tm>. Acesso em: 17 nov. 2011.

IUDÍCIBUS, Sérgio de. Teoria da Contabilidade. 5. ed. São Paulo: Atlas, 1997.

LOPES, Alexsandro Broedel. MARTINS, Eliseu. Teoria da contabilidade: uma nova abordagem. São Paulo: Atlas, 2007.

SANTOS, João José dos. IFRS: Manual de Contabilidade Internacional. São Paulo: Lex, 2006.

SILVA, Antônio Carlos Ribeiro da. Metodologia da Pesquisa Aplicada à Contabilidade: Orientações de Estudos, Projetos, Artigos, Relatórios, Monografias, Dissertações, Teses. São Paulo: Atlas, 2003. 
TORRES, Fernando. Audiência discute norma para receita. Jornal Valor Econômico, 16/11/2011. Disponível em: <http://www.valor.com.br/impresso/cvm/audiencia-discutenorma-para-receita>. Acesso em: 17 nov. 2011.

WEFFORT, Elionor Farah Jreige. O Brasil e a Harmonização Contábil Internacional: Influências dos Sistemas Jurídicos e Educacional, da Cultura e do Mercado. São Paulo: Atlas, 2005.

YIN, Robert K. Estudo de caso planejamento e métodos. 4. ed. Porto Alegre: Bookman, 2010 . 